\title{
Analysis of glycosylated flavonoids extracted from sweet-cherry stems, as antibacterial agents against pathogenic Escherichia coli isolates
}

\author{
Alfredo Aires ${ }^{1 凶}$, Carla Dias², Rosa Carvalho ${ }^{3}$ and Maria José Saavedra² \\ 'Centre for the Research and Technology for Agro-Environment and Biological Sciences, CITAB, Universidade de Trás-os-Montes e Alto Douro, \\ UTAD, Quinta de Prados, Portugal; ${ }^{2}$ Animal and Veterinary research Centre, CECAV, Universidade de Trás-os-Montes e Alto Douro, UTAD, Quinta \\ de Prados, Portugal; ${ }^{3}$ Agronomy Department, Universidade de Trás-os-Montes e Alto Douro, UTAD, Quinta de Prados, Portugal
}

The aim of this study was to evaluate the bioactivity of flavonoids extracted from sweet-cherry stems which are often used by a traditional system of medicine to treat gastro-intestinal and urinary tract infections but lacking any consistent scientific evidence; moreover the information about the class of phenolics, their content and the potential bioactivity of such material is very scarce. Thus, in this context, we have set a research study in which we evaluated the profile and content of phenolics extracted from sweet-cherry stems through a conventional $\left(70^{\circ} \mathrm{C}\right.$ and $20 \mathrm{~min}$ ) and ultrasound assisted extraction $(40 \mathrm{kHz}$, room temperature and $20 \mathrm{~min}$ ). The extracts were phytochemically characterized by using an HPLC-DAD-UV/ VIS system and assayed by an in vitro minimum inhibitory concentration (MIC) bioassay against Escherichia coli isolates. Simultaneously, the total antioxidant activities were measured using the 2,2'-azinobis-3-ethylbenzothiazoline-6-sulphonate (ABTS+) radical cation assay. Our results indicate that sweet-cherry stems have a high content of sakuranetin, ferulic acid, $p$-coumaric acid, $p$ coumaroylquinic acid, chlorogenic acid and its isomer neochlorogenic acid. Their average levels were highly affected by the extraction method used $(p<0.001)$. The same trend was observed for total antioxidant activity and MIC values. The extracts produced with ultrasounds presented both, a higher total antioxidant activity and a lower minimum inhibitory concentration. Statistical analyses of our results showed a significant correlation $(p<0.01)$ of total antioxidant activity and minimum inhibitory concentration with phenolics present in the extracts studied. Thus, we can conclude that cherry stems can be further exploited to purify compounds and produce coproducts with enhanced biologically added value for pharmaceutical industry.

Key words: flavonoids, agro-food wastes, enhanced extraction, antimicrobial agents, pathogenic bacteria

Received: 15 June, 2016; revised: 08 August, 2016; accepted: 13 February, 2017; available on-line: 14 April, 2017

e-mail: alfredoa@utad.pt

Abbreviations: ABTS'+ ${ }^{2}$ 2,2'-azinobis-3-ethylbenzothiazoline-6-sulphonat; ANOVA, two-way analysis of variance; IC50, inhibition concentration at $50 \%$ inhibition; MIC, minimum inhibitory concentration; SPSS, statistical Package for the Social Sciences; TAA total antioxidant activity; UAE, ultrasound assisted extraction; S.D., standard deviation.

\section{INTRODUCTION}

In the last decades, several studies have been published about the protective effect of phytochemicals from fruits, vegetables and medicinal plants or even some plant residues against important inflammatory and neurodegenerative diseases (Bansode et al., 2012; Sánchez-Vioque et al., 2013).This protection is often ascribed to the content of vitamins, minerals, oils, and secondary metabolites such as phenolic acids, flavonoids and anthocyanins. The richness and diversity of polyphenols in foods and crops have been two of the major reasons for looking to foods and their wastes as the source of natural phytochemicals with anti-inflammatory, antimicrobial and neuroprotective effects (Lobo et al., 2012). Every year, several tons of different types of food wastes are generated by the industry, without any substantial usage. Among them, fruit peduncles, leaves, stems, peels, barks and seeds are largely neglected, but according to the literature the content of bioactive compounds in these parts, when compared to the edible counterparts, can be sometimes higher (Fernando et al., 2013). In a recent review (Ajil et al., 2012), it was reported that food industry wastes can reach nearly $30 \%$ of the worldwide agricultural production, and those materials can comprise several nutraceutical compounds, such as polyphenols, carotenoids and dietary fibers. The same trend is observed in Portugal, a traditional producer of fruits and vegetables, in which every year tons of wastes from crops, including cherry (peduncles), are produced without any substantial use, despite their traditional use in folk medicine in infusions and decoctions used as diuretic and anti-inflammatory beverages (Sargin et al., 2013). Although the chemical composition of sweet-cherry is well established (Ballisteri et al., 2013; Alfieri et al., 2104), limited information is available about the phytochemical composition and bioactivities of their wastes.

Another important issue related to the use of natural compounds has been the search for new and effective compounds against recurrent bacterial infections, particularly those associated with the antibiotic resistance phenomena. Although new generations of antibiotics were produced by pharmacological industries (Coates et al. 2011), several antibiotics have failed to discourage the growth of many bacteria, including Escherichia coli, one of the most prevalent Gram-negative pathogen causing several diseases in humans and animals, particularly in poor communities (Da Silva et al., 2012). Although antimicrobial therapy is a significant tool in the treatment of these infections, their widespread resistance has become a great concern in the human and veterinary medicine (Schoevaerdts et al., 2011). Therefore, in the recent years we have assisted in an increment of research studies about 
the use of natural compounds, extracted from plants, against important pathogenic human and animal agents. In fact, plants have an almost infinite ability to produce compounds with different bioactive purposes that the humans and animals cannot synthesize. Therefore, they can be very useful for finding new, simple or complex compounds with antimicrobial activity. Thus, the aim of this study was to evaluate the phytochemical potential and the biological value of cherry wastes in order to extract effective phytochemicals against E. coli isolates. Additionally, the goal was to assess if these by-products can withstand the industrial processes of extraction used for production of coproducts with a highly added value for supplements or pharmaceutical applications.

\section{MATERIALS AND METHODS}

General experimental procedure. To develop this work, 1 kilogram of plant wastes from sweet-cherry (Prunus avium L.), was directly collected from a Portuguese private company from the food industry transformation sector. The sweet-cherry wastes were collected and separated into leaves and stems. The leaves were discharged and the stems were used in this study. The stems were then dehydrated in a freeze-dry system (UltraDrySystems ${ }^{\text {TM }}$, USA), milled and reduced to a fine powder, and stored in dark flasks at $4^{\circ} \mathrm{C}$ in a dark environment until chemical extraction. For extraction of phytochemicals, two different methods were performed in order to establish a simple, practical and feasible extraction procedure: 1) a conventional extraction and 2) an ultrasound assisted extraction (UAE).
Extraction. In the conventional extraction, $100 \mathrm{mg}$ of dry powder was added to a screw cap tube $(10 \mathrm{~mL})$ and mixed with $10 \mathrm{~mL}$ of the extraction solution $(70 \%$ methanol). Next, each suspension was agitated by vortexing (Genie 2, Fisher Scientific, UK) and heated at $70^{\circ} \mathrm{C}$ (1083, GFL-Gesells chaft ffur Labortechnik mbH, Germany) for 20 minutes, with agitation taking place every 5 minutes. Then, the mixtures were centrifuged at $4000 \mathrm{rpm}$ for $5 \mathrm{~min}$ (Kubota, Japan), filtered (Whatman No. 1 paper) and completely dried in a rotary evaporator under vacuum. The residues were then re-suspended in 10\% dimethyl sulfoxide (DMSO, Sigma-Aldrich, Tauferkichen, Germany) to obtain a final concentration of $5 \mathrm{mg} \times \mathrm{mL}^{-1}$. This final suspension was stored at $-20^{\circ} \mathrm{C}$ until subsequent analysis. In the UAE extraction, the same amount of dry powder of each sample that was used in the conventional method was weighed into $10 \mathrm{~mL}$ screw cap tubes, mixed with $10 \mathrm{~mL}$ of the extraction solution $(70 \%$ methanol), and placed in an ultrasonic bath device (Bandelin Electronics, Berlin, Germany) $(34 \mathrm{~cm} \times 10 \mathrm{~cm} \times 31 \mathrm{~cm})$, with $40 \mathrm{kHz}$ transducers annealed to the bottom. The ultrasonic device was turned on for the pre-set extraction time (20 minutes) at room temperature $\left(20 \pm 0.1^{\circ} \mathrm{C}\right)$. Then, the extracts were centrifuged at $4000 \mathrm{rpm}$ for $15 \mathrm{~min}$ (Kubota, Japan), the supernatants were collected, filtered (Whatman No.1 paper) and then submitted to the same final procedure as used for the conventional extraction.

Phytochemical analysis. The evaluation of phytochemical composition of each extract was performed by HPLC - DAD-UV/VIS system with $1 \%$ trifluoroacetic acid (TFA) (solvent A) and acetonitrile with $1 \%$ TFA (solvent B) as eluents. The elution was per-

Table 1. Phenolic compounds and respective retention time (Rt), wavelengths of maximum absorption in the visible region ( $\lambda_{\text {max }}$ ) of the studied by-product extracts (by order of elution).

\begin{tabular}{|c|c|c|c|c|}
\hline Phenolic compound identified & Rt (min) & $\begin{array}{l}\text { UV } \\
(\mathrm{nm})\end{array}$ & UV-DAD/VIS bands (nm) & Class \\
\hline Neochlorogenic acid & 14.89 & 320 & 244,300 sh, 326 & Hydroxycinnamic acid \\
\hline (+)-Catechin & 17.23 & 280 & 231,280 & Flavan-3-ols \\
\hline Cholorogenic acid & 17.39 & 320 & 243,300sh, 326 & Hydroxycinnamic acid \\
\hline$p$-Coumaric acid & 18.81 & 320 & 230, 277sh, 311 & Hydroxycinnamic acid \\
\hline (-)-Epicatechin & 19.60 & 280 & 232,279 & Flavan-3-ols \\
\hline Quercetin-3-O-rutinoside & 21.60 & 370 & 256,266 sh, 355 & Flavonol \\
\hline Kaempferol-3-O-rutinoside & 22.79 & 370 & 266, 329sh, 369 & Flavonol \\
\hline Ferulic acid & 23.13 & 320 & $244,296 s h, 328$ & Hydroxycinnamic acid \\
\hline Hydroxycynnamic acid derivative & 25.40 & 320 & $253,288,296$ & Hydroxycinnamic acid \\
\hline$p$-Coumaroylquinic acid & 26.54 & 320 & 261,312 & Hydroxycinnamic acid \\
\hline Apigenin & 26.89 & 370 & 230,268 sh, 338 & Flavonol \\
\hline Sakuranetin & 27.93 & 280 & 229,292 sh, 340 & Flavanone \\
\hline Isosakuranetin & 34.47 & 280 & $230,288 \mathrm{sh}, 340$ & Flavanone \\
\hline
\end{tabular}




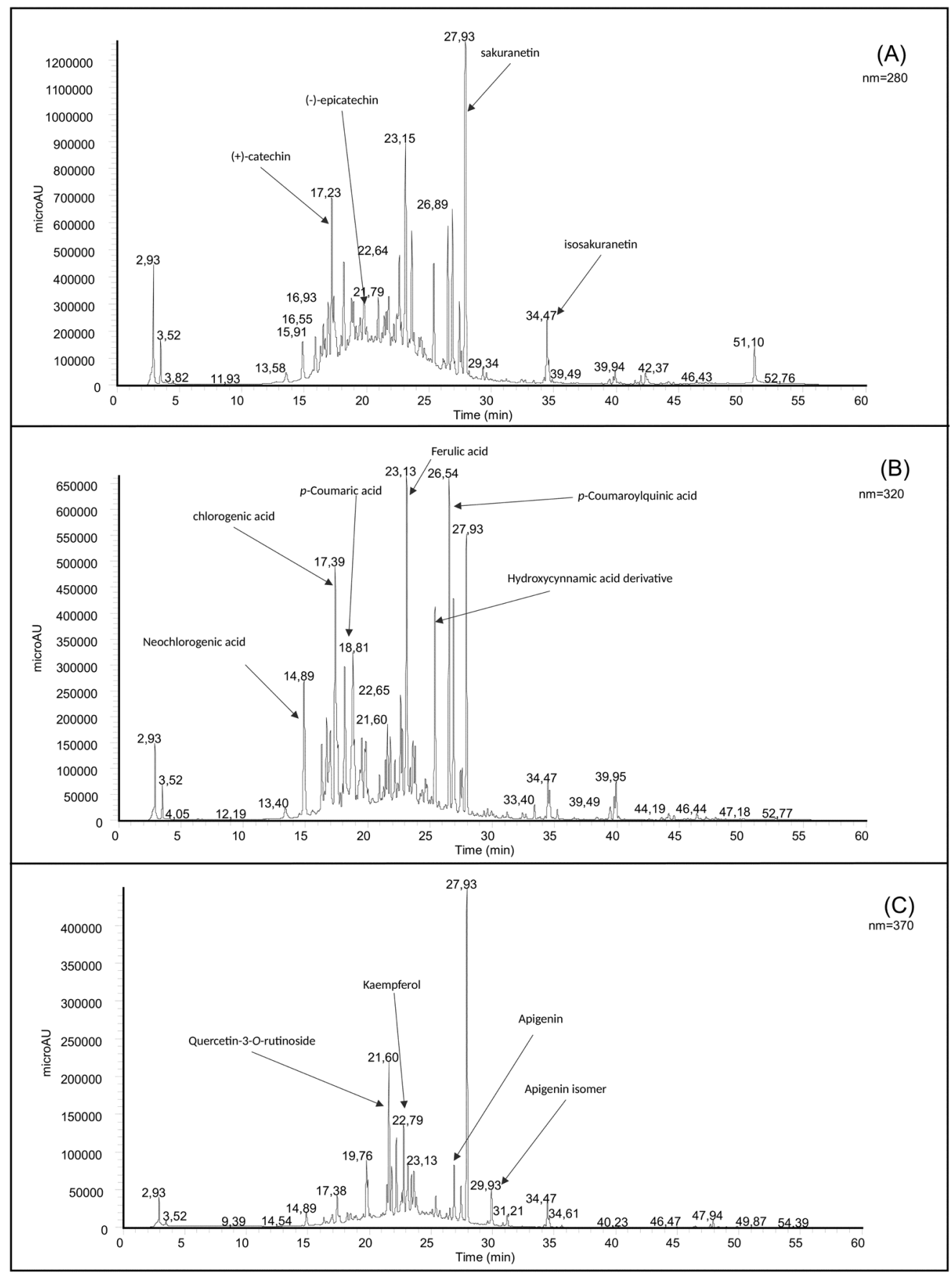

Figure 1. Chromatograms of sweet-cherry wastes (stems), recorded at different wavelengths: $280 \mathrm{~nm}(\mathrm{~A}), 320 \mathrm{~nm}$ (B) and $370 \mathrm{~nm}(C)$.

formed at a flow rate of $1 \mathrm{~mL} \mathrm{~min}^{-1}$ of solvent, with the gradient starting with $100 \%$ of water, and the injection volume of $10 \mu \mathrm{L}$. Chromatograms were recorded at 280, 320, 370 and $520 \mathrm{~nm}$ with a C18 column $(250 \times 46 \mathrm{~mm}, 5 \mu \mathrm{m})$. Phytochemicals were identified using peak retention time, UV spectra and UV max absorbance bands, and compared with those found for external commercial standards and in the literature. The quantification was made using internal (naringin, Sigma-Aldrich, Germany), and external standards. The external standards (-)-epicatechin, (+)-Catechin, apigenin, chlorogenic acid, ferulic acid, kaempferol-3-Orutinoside, isosakuranetin, neochlorogenic acid, $p$-coumaric acid, quercetin-3-O-rutinoside and sakuranetin, were purchased from Extrasynthese (Cedex, France). All standards were freshly prepared in $70 \%$ methanol

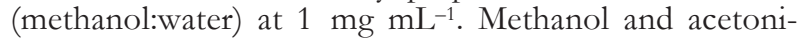
trile were purchased from Panreac chemistry (Lisbon, Portugal) and Sigma-Aldrich (Taufkirchen, Germany), respectively. The aqueous solutions were prepared using ultra-pure water (Milli-Q, Millipore).

Total antioxidant activity (TAA) in vitro bioassay. Simultaneously with the phytochemical determination, the TAA was measured by an in vitro $2,2^{\prime}$-azinobis3-ethylbenzothiazoline-6-sulphonate $\left(\right.$ ABTS $\left.^{\bullet+}\right)$ radical cation assay and was determined in a 96-well microplate. ABTS was generated by mixing a $7 \mathrm{mM}$ ABTS at pH $7.4\left(5 \mathrm{mM} \mathrm{NaH}_{2} \mathrm{PO}_{4}, 5 \mathrm{mM} \mathrm{Na}_{2} \mathrm{HPO}_{4}\right.$ and 154 
Table 2. Average levels of individual polyphenols identified in the cherry wastes, expressed as $\mu \mathrm{g} \mathrm{g}^{-1} \mathrm{dw}$

\begin{tabular}{lccc}
\hline Phenolics & Conventional & UAE & $p$-Value \\
\hline Neochlorogenic acid & $145.3 \pm 0.4$ & $167.2 \pm 0.4$ & $p<0.001$ \\
\hline $\begin{array}{l}\text { (+)-Catechin } \\
\text { Cholorogenic acid }\end{array}$ & $159.1 \pm 0.4$ & $225.4 \pm 0.6$ & $p<0.001$ \\
\hline $\begin{array}{l}\text { p-Coumaric acid } \\
\text { (-)-Epicatechin }\end{array}$ & $77.3 \pm 0.2$ & $92.9 \pm 0.2$ & $p<0.001$ \\
\hline $\begin{array}{l}\text { Quercetin-3-O-ruti- } \\
\text { noside }\end{array}$ & $67.3 \pm 0.2$ & $110.2 \pm 0.3$ & $p<0.001$ \\
\hline $\begin{array}{l}\text { Kaempferol-3-O-ruti- } \\
\text { noside }\end{array}$ & $38.9 \pm 0.1$ & $39.7 \pm 0.1$ & $p<0.01$ \\
\hline $\begin{array}{l}\text { Ferulic acid } \\
\text { Sakuranetin }\end{array}$ & $261.3 \pm 0.7$ & $278.7 \pm 0.7$ & $p<0.001$ \\
\hline $\begin{array}{l}\text { Hydroxycynnamic acid } \\
\text { derivative }\end{array}$ & $130.3 \pm 0.3$ & $159.9 \pm 0.4$ & $p<0.001$ \\
\hline \begin{tabular}{l} 
A Coumaroylquinic \\
\hline
\end{tabular} & $209.0 \pm 0.5$ & $251.0 \pm 0.6$ & $p<0.001$ \\
\hline
\end{tabular}

${ }^{1}$ Values expressed as mean \pm S.D. of three replicates. ${ }^{2}$ Probability test values obtained by ANOVA variance analysis.

$\mathrm{mM} \mathrm{NaCl}$ ) with $2.5 \mathrm{mM}$ potassium persulfate (final concentration) followed by storage in the dark at room temperature for $16 \mathrm{~h}$ before use. The mixture was diluted with ethanol to give an absorbance of $0.70 \pm 0.02$ units at $734 \mathrm{~nm}$ when using a U-2000 spectrophotometer (serial 121-0120, Hitachi Ltd., Tokyo, Japan). For each sample, several dilutions $(100 \mu \mathrm{L})$ in decreasing concentrations starting from $5 \mathrm{mg} \times \mathrm{mL}^{-1}$, were allowed to react with a fresh ABTS solution $(900 \mu \mathrm{L})$, and then the absorbance was measured 6 min after initial mixing. The TAA was expressed as follows: TAA (\%) =

Table 3. Antimicrobial properties of sweet-cherry wastes based on minimum inhibitory concentration (MIC)

\begin{tabular}{lccc}
\hline Extraction method & Bacterial isolates & $\begin{array}{c}\text { MIC (mg mL-1 of total } \\
\text { polyphenols })\end{array}$ & $\begin{array}{c}\text { Antibacterial } \\
\text { effect }{ }^{1}\end{array}$ \\
\hline E. coli MJS 260 & 0.250 & High \\
\hline Conventional extraction & E. coli MJS 294 & 0.250 & High \\
\hline E. coli JH270 & 0.125 & High \\
\hline UA extraction & E.coli MJS260 & 0.250 & High \\
\hline E. coli MJS 294 & 0.125 & High \\
\hline E. coli JH270 & 0.125 & High \\
\hline
\end{tabular}

'Antimicrobial activity is considered: very high, if $\mathrm{MIC}<100 \mu \mathrm{g} \times \mathrm{mL}^{-1}$; high, when $100<\mathrm{MIC} \leq 500$ $\mu \mathrm{g} \times \mathrm{mL}^{-1}$; moderate, when $500<\mathrm{MIC}<1000 \mu \mathrm{g} \times \mathrm{mL}^{-1}$; weak, when $\mathrm{MIC}=1000 \mu \mathrm{g} \times \mathrm{mL}^{-1}$, and null, if $\mathrm{MIC}>1000 \mu \mathrm{g} \times \mathrm{mL}^{-1}$.
$[(($ solvent absorbance - sample absorbance)/solvent absorbance) $\times 100]$. All determinations were performed in triplicate. The half maximal inhibitory concentration $\left(\mathrm{IC}_{50}\right)$ was determined in order to compare the TAA, and lower $\mathrm{IC}_{50}$ means better radical scavenging activity.

In vitro antimicrobial activity bioassay. After the determination of TAA, an in vitro bioassay of antimicrobial activity of extracts against bacterial pathogenic isolates was performed. For that, Gram-negative isolates of Escherichia coli collected from gastrointestinal tract segments, isolated and purified at the Microbiology laboratory of University of Trás-os-Montes e Alto Douro, were used. The identifications were performed by means of standard biochemical classification techniques (Murray et al. 1999), using API 20E, API 20NE, API Staphy and API Step (BioMerieux), according to the procedure described previously (Joergensen et al., 2009), followed by genetic identification through 16S rRNA sequencing. After this identification, a minimum inhibitory concentration (MIC) assay (Simões et al., 2009) in 96-well microplates was performed. It is widely accepted that phytochemicals are routinely classified as antimicrobials on the basis of susceptibility tests that yield minimum inhibitory concentration (MIC) in the range of $100-1000 \mu \mathrm{g} \mathrm{mL}-1$ (Sarker et al., 2007). Thus, we prepared different extracts with a maximum concentration of $1000 \mu \mathrm{g}$ of total phenolics in $10 \%$ DMSO. Next, $100 \mu \mathrm{L}$ of each extract $(1000 \mu \mathrm{g}$ of total phenolics in $10 \%$ DMSO) and $1000 \mu \mathrm{g}$ of a standard antibiotic were added into the first row of the 96 well microplates. Then, two fold serial dilutions were performed in additional wells containing $100 \mu \mathrm{L}$ of nutrient broth. Then, bacterial suspensions $(20 \mu \mathrm{L})$ were added to each well to obtain a concentration of $5 \times 10^{5} \mathrm{cfu} \mathrm{mL}^{-1}$ and $20 \mu \mathrm{L}$ of the resazurin indicator solution (prepared by dissolving a $270 \mathrm{mg}$ tablet in $40 \mathrm{~mL}$ of sterile doubledistilled water) were finally added into each well. Positive and negative controls were included: a column with a ciprofloxacin (Oxoid, England) served as a positive control, and three negative controls were used (a column without any bioactive compounds, a column without the bacterial solution $(20 \mu \mathrm{L}$ of nutrient broth was used instead) and a column with a DMSO solution). The plates were then incubated at $37^{\circ} \mathrm{C}$ for $24 \mathrm{~h}$, and the color changes were assessed visually. Bacterial growth was indicated by color modification from purple to pink (or colorless) and the MIC was defined as the lowest concentration of the tested extract or antibiotic that completely inhibited the visible bacterial growth. This assay was done in triplicate. To classify the antimicrobial activity effect, the following criteria were established (Kuete et al., 2011): very high, if MIC values were below $100 \mu \mathrm{g} \mathrm{mL}-1$; high, when $100<\mathrm{MIC}<625 \mu \mathrm{g} \mathrm{mL}^{-1}$; moderate, when $625<$ MIC $\leq 1000$ $\mu \mathrm{g} \mathrm{mL} \mathrm{m}^{-1}$; and null, if $\mathrm{MIC}>1000$ $\mu \mathrm{g} \mathrm{mL}^{-1}$. All determinations were performed in triplicate.

Statistical analysis. All data were expressed as mean values $\underline{ \pm}$ standard deviation (S.D.). The results were analyzed using one-way ANOVA, followed by the Duncan multiple range test, based on 


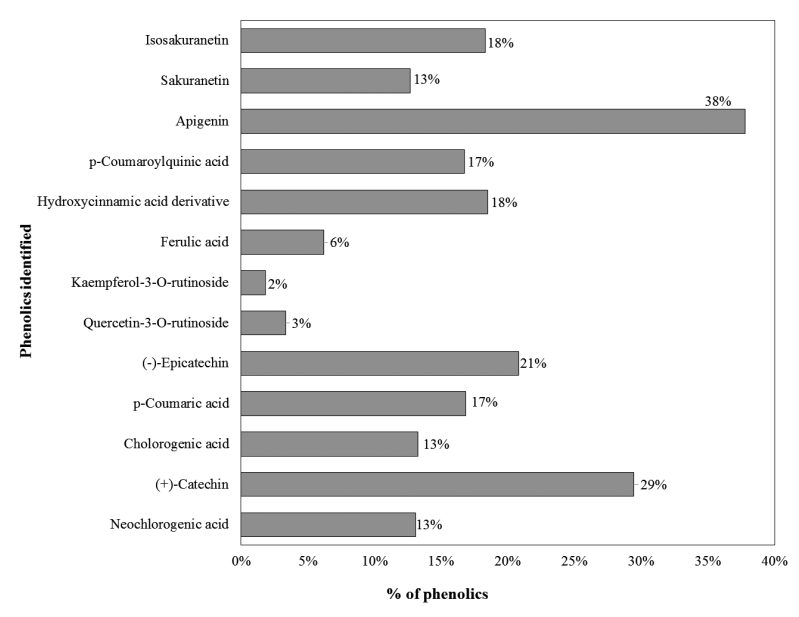

Figure 2. Increment in phenolic content when UAE method is used, when compared to a conventional method, expressed as percentage (\%).

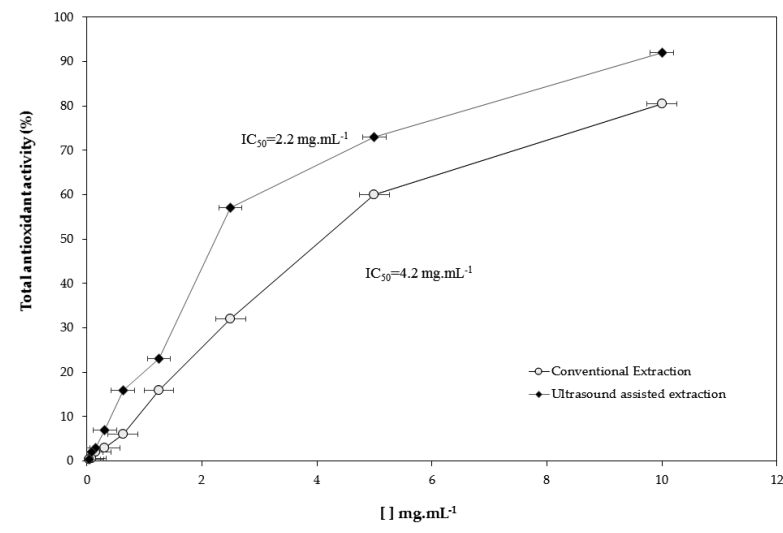

Figure 3. Graphical representation of total antioxidant activity (TAA) determined at different extract concentration. $I_{50}$ values are included in the graph.

confidence level equal or higher than 95\% $(p<0.05)$. A Pearson's correlation was performed to establish a clear trend between bioactivities (TAA and MIC) and the levels of phytochemicals. The SPSS v.17 software (SPSSIBM, Orchard Road-Armonk, New York, NY, USA) was used to carry out this analysis.

\section{RESULTS AND DISCUSSION}

The results of the polyphenol profile determined by HPLC are presented in Table 1 and Fig. 1. The average content of each polyphenol determined in this study is presented in Table 2. The analysis revealed different types of polyphenols grouped into flavanones, flavan3 -ols and hydroxycinnamic acid types (Table 1), and higher levels were found for sakuranetin + isosakuranetin (on average, $35 \%$ of total polyphenols identified), neochlorogenic acid and chlorogenic acid $(14.5 \%$ of total polyphenols identified), $p$-coumaric acid $+p$-coumaroylquinic acid $(13.6 \%$ of total polyphenols identified), ferulic acid (11.6\% of total polyphenols identified) and + catechin + epicatechin $(12.5 \%$ of total polyphenols identified) (Table 2). The highest levels for each polyphenol were consistently obtained for the extracts produced with the UAE method when compared to those obtained by a conventional method $(p<0.001)$.
Table 4. Pearson's coefficient correlations ${ }^{1,2}$

\begin{tabular}{|c|c|c|}
\hline & $\mathrm{IC}_{50}$ values & $\begin{array}{l}\text { Minimum inhibitory } \\
\text { concentration (MIC) }\end{array}$ \\
\hline \multirow{2}{*}{ Neochlorogenic acid } & $-0.9996^{* *}$ & $-0.9996^{* *}$ \\
\hline & $(p<0.001)$ & $(p<0.001)$ \\
\hline \multirow{2}{*}{ (+)-Catechin } & $-0.9999^{* *}$ & $-0.9999 * *$ \\
\hline & $(p<0.001)$ & $(p<0.001)$ \\
\hline \multirow{2}{*}{ Cholorogenic acid } & $-0.9996^{* *}$ & $-0.9996^{* *}$ \\
\hline & $(p<0.001)$ & $(p<0.001)$ \\
\hline \multirow{2}{*}{$p$-Coumaric acid } & $-0.9998^{* *}$ & $-0.9998^{* *}$ \\
\hline & $(p<0.001)$ & $(p<0.001)$ \\
\hline \multirow{2}{*}{ (-)-Epicatechin } & $-0.9998^{* *}$ & $-0.9998^{* *}$ \\
\hline & $(p<0.001)$ & $(p<0.001)$ \\
\hline \multirow{2}{*}{ Quercetin-3-O-rutinoside } & $-0.9929 * *$ & $-0.9729^{* *}$ \\
\hline & $(p<0.001)$ & $(p<0.001)$ \\
\hline \multirow{2}{*}{$\begin{array}{l}\text { Kaempferol-3-O-rutino- } \\
\text { side }\end{array}$} & $-0.9730^{* *}$ & $-0.9760^{* *}$ \\
\hline & $(p<0.001)$ & $(p<0.001)$ \\
\hline \multirow{2}{*}{ Ferulic acid } & $-0.9780^{* *}$ & $-0.9880^{* *}$ \\
\hline & $(p<0.001)$ & $(p<0.001)$ \\
\hline \multirow{2}{*}{$\begin{array}{l}\text { Hydroxycynnamic acid } \\
\text { derivative }\end{array}$} & $-0.9998^{* *}$ & $-0.9998^{* *}$ \\
\hline & $(p<0.001)$ & $(p<0.001)$ \\
\hline \multirow{2}{*}{ p-Coumaroylquinic acid } & $-0.9997^{* *}$ & $-0.9997^{* *}$ \\
\hline & $(p<0.001)$ & $(p<0.001)$ \\
\hline \multirow{2}{*}{ Apigenin } & $-0.9976^{* *}$ & $-0.9983^{* *}$ \\
\hline & $(p<0.001)$ & $(p<0.001)$ \\
\hline \multirow{2}{*}{ Sakuranetin } & $-0.9995^{* *}$ & $-0.9995^{* *}$ \\
\hline & $(p<0.001)$ & $(p<0.001)$ \\
\hline \multirow{2}{*}{ Isosakuranetin } & $-0.9998^{* *}$ & $-0.9997^{* *}$ \\
\hline & $(p<0.001)$ & $(p<0.001)$ \\
\hline
\end{tabular}

${ }_{1 * *}$ Correlation is significant at the 0.01 level; ${ }^{*}$ Correlation is significant at the 0.05 level. 2 In brackets, the respective $p$ value is given.

The general tendency observed was increment in phenolic contents when the UAE method was used. The average levels of phenolic increments, obtained with UAE when compared to the conventional method, varied between $2 \%$ and $38 \%$ (Fig. 2), and the apigenin, catechin, epicatechin, sakuranetin and isosakuranetin flavonoids, were the flavonoids with the highest percentage of increment (Fig. 2). This trend is in agreement with previous studies (Schneider et al. 2006; Ashokkumar et al., 2008; Tiwari et al., 2010) where an increment in the phenolic contents was found, particularly of the flavonoid types, when UAE was used to extract them. The increment of pressure during sonication provokes the decomposition of radicals and the hydroxylation of aromatic rings into ortho-, meta- and 


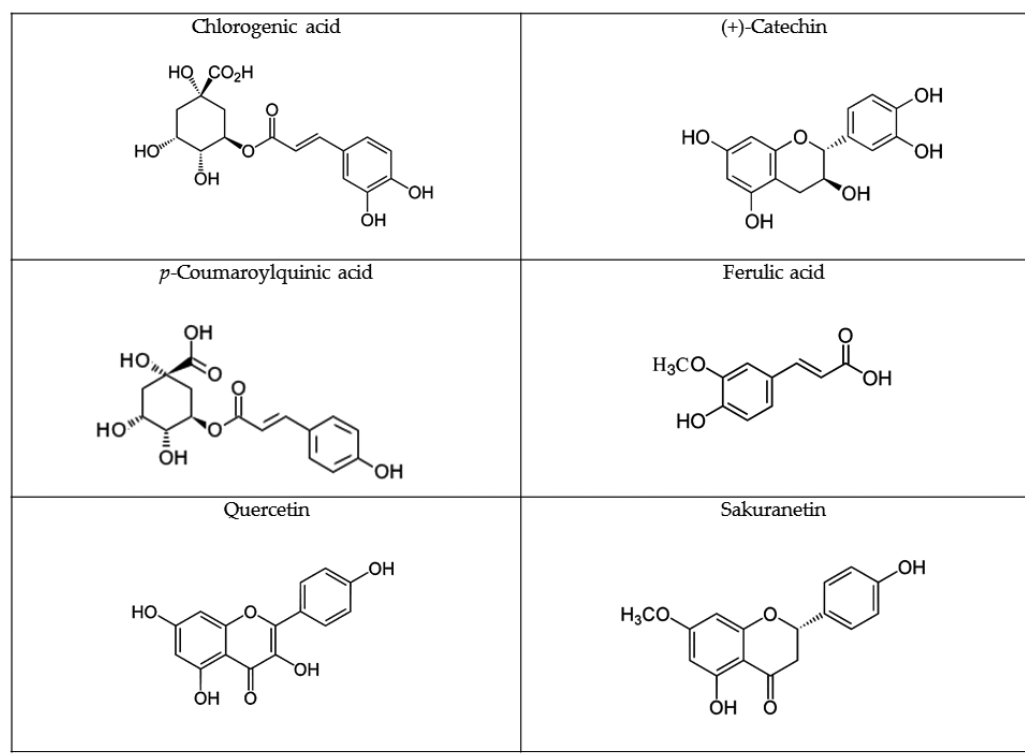

Figure 4. Chemical parent structures of the phenolics identified in the current study.

para-positions, increasing their solubility and movement from cells towards the solvents (Ashokkumar et al., 2008; Tiwari et al., 2010), and thus incrementing their concentration in extracted solutes. However, the amplitude of this effect is dependent on intrinsic properties of the matrices and extraction factors, such as the temperature, pH, light, and time (Alihourchoi et al., 2013). Based on our results, the UAE seems to be very effective since it increases extraction of polyphenols from the flavonoid class. A similar trend was found in the TAA (Fig. 3) and the antimicrobial activity bioassays (Table 3). In these experiments, the extracts produced with UAE yielded the lowest values of $\mathrm{IC}_{50}$ (Fig. 3) and the lowest average values of MIC (Table 3 ) against all E. coli isolates as well.

To understand which type of compounds is determinant for these bioactivities, we performed a determination of the Pearson's correlation (between the MICs, $\mathrm{IC}_{50}$ values and average content of each polyphenol detected in samples), and the results presented in Table 4 indicate that MICs and $\mathrm{IC}_{50}$ values are highly dependent on the combined effect of the different polyphenols. Nonetheless, some compounds, such as sakuranetin, isosakuranetin, neochlorogenic and chlorogenic acid, catechin and the epicatechin derivative, $p$-coumaric acid and the $p$-coumaroylquinic acid derivative, had shown to be highly preponderant for $\mathrm{IC}_{50}$ and MIC average levels (Table 4). These compounds presented the highest negative correlation coefficients, which means that the higher they were, the lower the IC50 and MIC values were, and thus the highest TAA and antimicrobial activity. Our findings are important since they reinforce some recent conclusions about the antioxidant capacity and antimicrobial effect of such compounds (Wong et al., 2011; Shimizu et al., 2012). The ability of these compounds to modify cell structures and cause deformations in their structure, and as a consequence the loss of functionality, was recently observed (Denev et al., 2014). Their chemical structure is based on two, three or more aromatic hydroxyl compounds, as we have detected (see Fig. 4), and a system of delocalized electrons is very effective against several microorganisms due to its interference with cellular membranes (Ultee et al., 2002). Compounds with two or more aromatic hydroxyl groups have high affinity to bacterial membranes, causing destabilization of the outer membrane, leading to a decrease in the membrane potential and thus, an additional decrease in the $\mathrm{pH}$ as a result of a hydroxyl group presence and a system of delocalized electrons (Ultee et al., 2002). Tsai et al. (2012) also found a high affinity of the neochlorogenic acid to bacterial cellular membranes, interfering with both, the membrane and cytoplasmic organelles and acting as protoplasmic poisons, thus, being highly effective in supressing the Gram-negative bacterial isolates. Similar situation was observed by Park et al. (2014) for several other microorganisms and different Gram-negative isolates. Thus, we can conclude that the presence of sakuranetin, isosakuranetin, neochlorogenic and chlorogenic acid were highly determinant for the antibacterial activity exhibited by sweetcherry extracts against E. coli. These results explain, scientifically, why in several countries like Portugal, the stems from sweet-cherry are largely used in folkloric and traditional medicine as tea, decoctions or infusions, for depurative, anti-inflammatory and antimicrobial therapy, particularly in the treatment of several urinary tract infections, mostly caused by E. coli strains. Based on our results, the pointed bioactivities for sweetcherry stems are highly correlated with the reported flavonoids and phenolic acids. To conclude, the bioactivities found in the current study can be the starting point for further exploitation of such by-products as additives or supplements. Our results seem to demonstrate the usefulness of sweet-cherry wastes to extract bioactive compounds with enhanced bioactivity, particularly phenolic acids and flavanones.

\section{Acknowledgements}

The authors acknowledge the financial support provided by the FCT-Portuguese Foundation for Science and Technology (Alfredo Aires-SFRH/BPD/65029/2009) under the QREN-POPH-Tipologia 4.1-Formação Avançada program.

\section{Conflict of Interest}

No conflict of interest declared.

\section{REFERENCES}

Ajil CM, Brar SK, Verma M, Tyagi RD, Godbout S, Valéro JR (2012) Bio-processing of agro-byproducts to animal feed. Crit Rev Biotechnol 32: 382-400. doi: 10.3109/07388551.2012.659172

Alfieri M, Hidalgo A, Berardo N, Redaelli RJ (2014) Carotenoid composition and heterotic effect in selected Italian maize germplasm. Cereal Sci 59: 181-188. doi:10.1016/j.jcs.2013.12.010

Alighourchi HR, Barzegar M, Sahari MA, Abbasi S (2013) Effect of sonication on anthocyanins, total phenolic content, and antioxidant capacity of pomegranate juices. Int Food Res J 20: 1703-1709

Ashokkumar M, Sunartio D, Kentish S, Mawson R, Simons L, Vilkhu K, Versteeg C K (2008) Modification of food ingredients by ultrasound to improve functionality: A preliminary study on a model system. Innov Food Sci Emerg Technol 9: 155-160. doi:10.1016/j.ifset.2007.05.005

Ballisteri G, Continella A, Gentile A, Amenta M, Fabroni S, Rapisarda P (2013) Fruit quality and bioactive compounds relevant to human health of sweet cherry (Prunus avium L.) cultivars grown in Italy. Food Chem 140: 630-638. doi:10.1016/j.foodchem.2012.11.024 
Bansode RR, Randolph P, Hurley S, Ahmedna M (2012) Evaluation of hypolipidemic effects of peanut skin-derived polyphenols in rats on Western-diet. Food Chem 135: 1659-1666. doi: 10.1016/j.foodchem.2012.06.034

Coates ARM, Halls G, Hu Y (2011) Novel classes of antibiotics or more of the same? Brit J Pharmacol 163: 184-194. doi: 10.1111/j.1476-5381.2011.01250.x

Da Silva GJ, Mendonca N (2012) Association between antimicrobial resistance and virulence in Escherichia coli. Virulence 3: 18-28. doi: 10.4161/viru.3.1.18382

Denev P, Kratchanova M, Cizb M, Lojek A, Vasicek O, Nedelcheva P Blazheva D, Toshkova R, Gardeva E, Yossifova L, Hyrsl P, Vojtek L (2014) Biological activities of selected polyphenol-rich fruits related to immunity and gastrointestinal health. Food Chem 157: 37-44. doi: 10.1016/j.foodchem.2014.02.022

Fernando IDNS, Abeysinghe DC, Dharmadasa RM (2013) Determination of phenolic contents and antioxidant capacity of different parts of Withania somnifera (L.) Dunal from three different growth stages. Ind Crop Prod 50: 537-539. doi:10.1016/j.indcrop.2013.08.042

Jorgensen JH, Turnidge JD, Washington JA (2009) Antibacterial susceptibility tests: dilution and disk diffusion methods In Manual of clinical microbiology, 7th edn, Murray PR, Baron EJ, Pfaller MA, Tenover FC, Yolken RH eds, pp 1526e154

Kuete V, Alibert-Franco S, Eyong KO, Ngameni B, Folefoc GN, Nguemeving JR, Tangmouo JG, Fotso GW, Komguem J, Ouahouo BM, Bolla, JM, Chevalier J, Ngadjui BT, Nkengfack AE, Pages JM (2011) Antibacterial activity of some natural products against bacteria expressing a multidrug-resistant phenotype. Int J Antimicrob Ag 37: 156-161. doi: 10.1016/j.ijantimicag.2010.10.020

Lobo V, Patil A, Phatak A, Chandra N (2012) Free radicals, antioxidants and functional foods: Impact on human health. Pharmacogn Rev 4: 118-126. doi: 10.4103/0973-7847.70902

Murray PR, Boron EJ, Pfaller MA, Tenover F, Yolken RH (1999) ASM Press: Washington, DC pp 876

Park HL, Yoo Y, Hahn TR, Bhoo SH, Lee SW, Cho MH (2014) Antimicrobial activity of UV-induced phenylamides from rice leaves. Molecules 19: 18139-18151. doi: 10.3390/molecules191118139

Sánchez-Vioque R, Polissiou M, Astraka K, de los Mozos-Pascual M, Tarantilis P, Herraiz-Peñalver D, Santana-Méridas O (2013) Polyphenol composition and antioxidant and metal chelating activities of the solid residues from the essential oil industry. Ind Crop Prod 49: 150-159. doi:10.1016/j.indcrop.2013.04.053
Sargin SA, Akçicek E, Selvi S (2013) An ethnobotanical study of medicinal plants used by the local people of Alaşehir (Manisa) in Turkey. J Ethnopharmacol 150: 860-874. doi: 10.1016/j.jep.2013.09.040.

Sarker SD, Nahar L, Kumarasamy Y (2007) Microtitre plate-based antibacterial assay incorporating resazurin as an indicator of cell growth, and its application in the in vitro antibacterial screening of phytochemicals. Methods 42: 321-324. doi: 10.1016/j.ymeth.2007.01.006

Schneider Y, Zahn S, Hofmann J, Wecks M, Rohm H (2006) Acoustic cavitation induced by ultrasonic cutting devices: A preliminary study. Ultrason Sonochem 13: 117-120. doi:10.1016/j.ultsonch.2005.09.002

Schoevaerdts D, Bogaerts P, Grimmelprez A, de Saint-Hubert M, Delaere B, Jamart J, Swine C, Glupczynski Y (2011) Clinical profiles of patients colonized or infected with extended-spectrum beta-lactamase producing Enterobacteriaceae isolates: a 20 month retrospective study at a Belgian University Hospital. BMC Infect Dis 11: 12. doi: 10.1186/1471-2334-11-12

Shimizu T, Lin F, Hasegawa M, Nojiri H, Yamane H, Okada K (2012) The potential bio-production of the pharmaceutical agent sakuranetin, a flavonoid phytoalexin in rice. Bioeng 3: 352-357. doi: 10.4161/ bioe. 21546

Simões, M, Bennett RN, Rosa, EAS (2009) Understanding antimicrobial activities of phytochemicals against multidrug resistant bacteria and biofilms. Nat Prod Rep 26: 746-757. doi: 10.1039/b821648g

Tiwari BK, Patras A, Brunton N, Cullen PJ, O'Donnell CP (2010) Ultrasound assisted extraction of bioactive compounds from Nephelium lappaceum L. fruit peel using central composite face centered response surface design. Ultra Sonochem 17: 598-604. doi: 10.1016/j. arabjc.2013.02.007

Tsai S-J, Huang C-S, Mong M-C, Kam W-Y, Huang H-Y, Yin M-CJ (2012) Anti-inflammatory and antifibrotic effects of naringenin in diabetic mice. Agr Food Chem 60: 514-521. doi: 10.1021/jf203259h

Ultee A, Bennik MHJ, Moezelaar R (2002) The phenolic hydroxyl group of carvacrol is essential for action against the food-borne pathogen Bacillus cereus. Appl Environ Microbiol 68: 1561-1568. doi: 10.1128/AEM.68.4.1561-1568.2002

Wong SL, Chang HS, Wang GJ, Chiang MY, Huang HY, Chen $\mathrm{CH}$, Tsai SC, Lin CH, Chen IS (2011) Secondary metabolites from the roots of Neolitsea daibuensis and their anti-inflammatory activity. J Nat Prod 74: 2489-2496. doi: 10.1021/np100874f 